\title{
A modeling analysis of a heavy air pollution episode occurred in Beijing
}

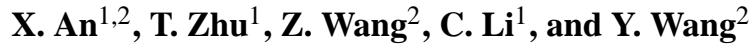 \\ ${ }^{1}$ State Key Joint Laboratory of Environmental Simulation and Pollution Control, Center for Environmental Sciences, Peking \\ University, Beijing 100871, China \\ ${ }^{2}$ LAPC/NZC, Institute of Atmospheric Physics, Chinese Academy of Sciences, Beijing 100029, China
}

Received: 17 July 2006 - Published in Atmos. Chem. Phys. Discuss.: 29 August 2006

Revised: 8 January 2007 - Accepted: 28 May 2007 - Published: 18 June 2007

\begin{abstract}
The concentrations of fine particulate matter (PM) and ozone in Beijing often exceed healthful levels in recent years, therefore China is to taking steps to improve Beijing's air quality for the 2008 Olympic Games. In this paper, the Models-3 Community Multiscale Air Quality (CMAQ) Modeling System was used to investigate a heavy air pollution episode in Beijing during 3-7 April 2005 to obtain the basic information of how heavy air pollution formed and the contributions of local sources and surround emissions. The modeling domain covered from East Asia with four nested grids with 81 to $3 \mathrm{~km}$ horizontal resolution focusing on urban Beijing. This was coupled with a regional emissions inventory with a $10 \mathrm{~km}$ resolution and a local $1 \mathrm{~km}$ Beijing emissions database. The trend of predicted concentrations of various pollutants agreed reasonably well with the observations and captured the main features of this heavy pollution episode. The simulated column concentration distribution of PM was correlated well with the MODIS remote sensing products. Control runs with and without Beijing emissions were conducted to quantify the contributions of non-Beijing sources (NBS) to the Beijing local air pollution. The contributions of NBS to each species differed spatially and temporally with the order of $\mathrm{PM}_{2.5}>\mathrm{PM}_{10}>\mathrm{SO}_{2}>$ soil for this episode. The percentage contribution of NBS to fine particle $\left(\mathrm{PM}_{2.5}\right)$ in Beijing was averaged about $39 \%$, up to $53 \%$ at the northwest of urban Beijing and only $15 \%$ at southwest. The spatial distribution of NBS contributions for $\mathrm{PM}_{10}$ was similar to that for $\mathrm{PM}_{2.5}$, with a slightly less average percentage of about $30 \%$. The average NBS contributions for $\mathrm{SO}_{2}$ and soil (diameter between $2.5 \mu \mathrm{m}$ and $10 \mu \mathrm{m}$ ) were $18 \%$ and $10 \%$. In addition, the pollutant transport flux was calculated and compared at different levels to investigate transport pathway and magnitude. It was found that the NBS contribution correlated with the transport flux, contributing $60 \%$ of $\mathrm{PM}_{10}$ concen-
\end{abstract}

Correspondence to: Z. Wang

(zifawang@mail.iap.ac.cn) tration in Beijing at the time of transport flux peak during a strong episode with a transport path from southwest to northeast.

\section{Introduction}

Regional air pollution over Mega-city clusters has been accompanied with the quick economical expansion in China. Mega-cities are significant sources of aerosols and oxidants, which are important atmospheric components having direct impacts on air quality and climate on a regional and even global scale. It is critical to understand the key chemical and physical processes controlling the concentrations of these species in these polluted regions. As a research hotspot, one of the dominant mega-city clusters is located in Beijing, the capital of China, and its surroundings areas (Fig. 1). With a population more than 14 million, Beijing's economy growth has been rapidly growing with an annual increasing rate exceeding $10 \%$ continuously. For example, the total energy consumption is increased from 38.5 million ton standard coal in 1999 to 45.1 million-ton standard coal in 2002, resulting in a very serious air pollution problem. After Beijing succeeded in the competition for the bid to host the 2008 Olympic Games, improving the air quality in Beijing has been one of the most important tasks for the Chinese government. After a series of air antipollution measures including increasing the natural gas supply, centralizing the heat supply, removing electric heat devices, and using of low sulfur coals, air quality in Beijing has improved gradually since 1997. The number of days of meeting Air Pollution Standard II or better increased from 56 days in 1998 to 254 days in 2005. However, the average concentration of main contaminants remained high in the past three years, indicating that emissions controls only in Beijing are not enough to solve the regional pollution problems over Beijing.

Published by Copernicus Publications on behalf of the European Geosciences Union. 


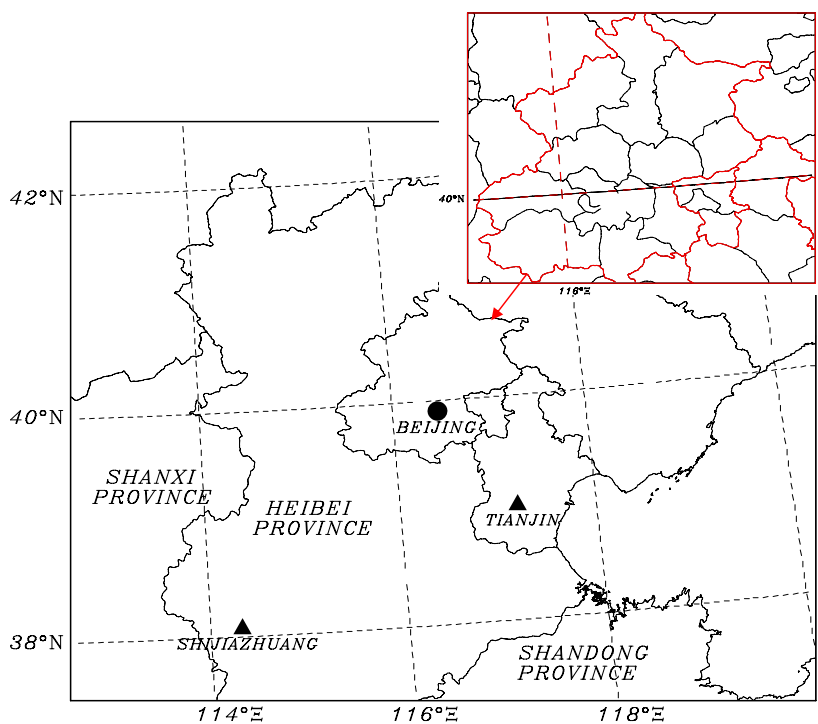

Fig. 1. Map of Beijing and surrounding areas.

Several studies pointed out that the regional air pollution in Beijing was caused not only by local sources but also significantly by non-Beijing sources (Zhang et al., 2004; Xu et al., 2004; Sun et al., 2004). The basin-like geophysical feature of urban Beijing and its unique weather system are the dominant factors influencing air quality (Ren et al., 2004). Su et al. (2004) investigated certain transport pathways of NBS to Beijing and found that a convergence zone of air pollutants occurred within the atmospheric boundary layer along the combination of the Yanshan-Taihang mountains and the North China Plain. The contribution of various emission sources shows a specific structure in spatial distribution and depends on the location and weather system.

In order to improve air quality in Beijing with comprehensive measures, it is necessary to quantitatively evaluate the contribution of NBS so that regional emissions can be controlled more efficiently. This can be achieved through a regional air quality modeling system. Yan et al. (2005) made a long-term simulation of $\mathrm{SO}_{2}$ and discussed the impacts of different types of sources on air quality. The transport of pollutants among several cities in North China was investigated by Zhang et al. (2004) with simplified chemical transport model, which considered no chemical reactions in simulating $\mathrm{PM}_{10}$.

In this study the formation process of a typical heavy air pollution episode in Beijing during 3-7 April 2005 was investigated with the Models-3/CMAQ. This episode clearly showed the typical evolution process of high particle pollution over Beijing with continuous several days' pollution. The temporal and spatial characteristics of the main contaminants were analyzed with a focus on the contributions of NBS to $\mathrm{SO}_{2}, \mathrm{PM}_{10}$ and $15 \mathrm{PM}_{2.5}$ concentrations in Beijing. The modeling results were also compared with observations of

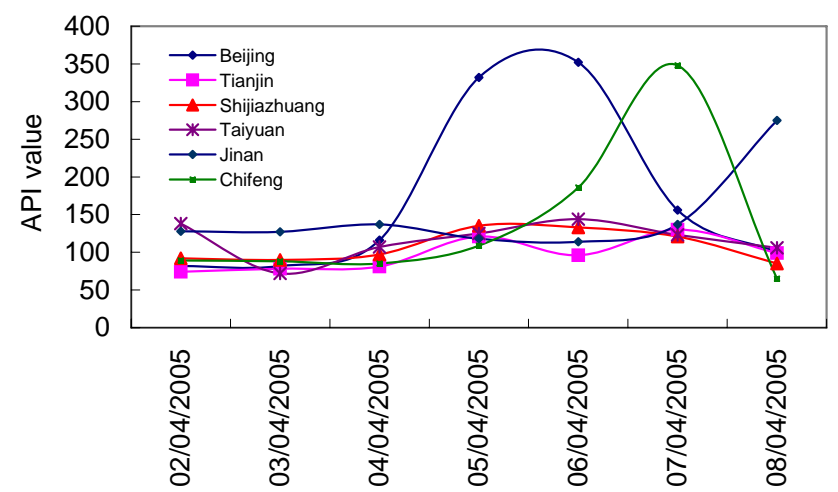

Fig. 2. API values of Beijing and surrounding cities from 2 to 8 April 2005.

$\mathrm{SO}_{2}$ and particle matters at a $325 \mathrm{~m}$ meteorological tower located on the campus of the Institute of Atmospheric Physics (IAP), meteorological data observed at six monitoring sites in Beijing, and satellite aerosol remote sensing results from NASA.

\section{Observations and regional patterns of the high air pollution episode}

\subsection{Air Pollution Index (API) of Beijing and surrounding} cities

To indicate the air pollution level over the Chinese cities, an Air Pollutant Index (API) is issued every day by SEPA (State Environment Protection Agency of China) with the monitoring data of suspended particulate matter $\left(\mathrm{PM}_{10}\right)$, sulfur dioxide $\left(\mathrm{SO}_{2}\right)$, and nitrogen dioxide $\left(\mathrm{NO}_{2}\right)$ (http://www.sepa.gov. $\mathrm{cn})$. An index value under 100 indicates the air quality of that monitoring station conforms to the National ambient air quality criteria II. A value over 100 will worsen the allergy symptom of unhealthy people. Figure 2 shows the time series of daily API of Beijing and surrounding cities in 2-8 April 2005. An obvious high pollution episode occurred in Beijing with API over 100 lasting more than 4 days from 4-7 April and reaching heavy pollution levels with a maximum API of 350 on 5-6 April.

\section{2 $\mathrm{SO}_{2}$ and particles observed at IAP $325 \mathrm{~m}$ tower}

Six platforms were made on the IAP tower for simultaneous collection of samples for analysis of $\mathrm{SO}_{2}$ and particulate matter. The 43CTL instruments of high precision impulse fluorescence (USA Thermion Environment Corporation) were used for measuring gas at $8 \mathrm{~m}, 47 \mathrm{~m}, 120 \mathrm{~m}$, and $280 \mathrm{~m}$. The RP1400a instruments (USA ANPU) were used for measuring mass concentration of the particles at $8 \mathrm{~m}$ and $240 \mathrm{~m}$. The available data shown in Fig. 3 for this study include $\mathrm{SO}_{2}$ at $47 \mathrm{~m}$ and $\mathrm{PM}_{10}$ at $8 \mathrm{~m}$. From Fig. 3, it can be seen that $\mathrm{SO}_{2}$ 


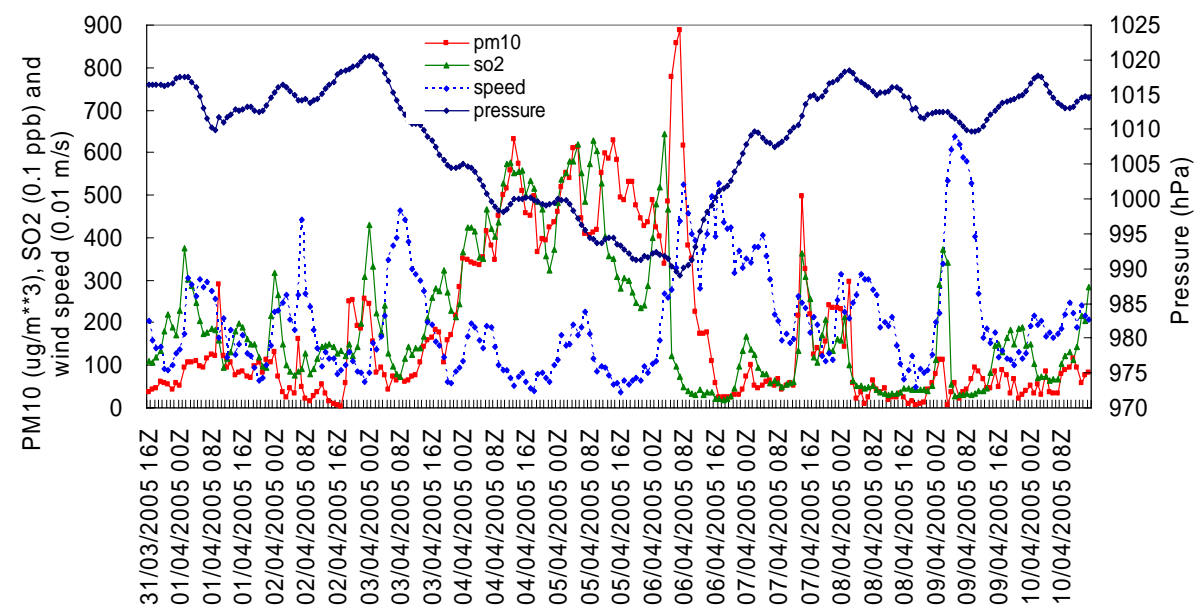

Fig. 3. Temporal variations of observed $\mathrm{SO} 2$ and particle concentrations of IAP site and average pressure, wind speed of six observations sites in Beijing from 31 March 2005 16:00 to 10 April 2005 16:00 (UTC).

concentrations were high on 4-6 April, with peak value exceeding $60 \mathrm{ppb}$. Hourly variations of $\mathrm{PM}_{10}$ has similar patterns with $\mathrm{SO}_{2}$ (Fig. 3), but with much higher levels reaching $300 \mu \mathrm{g} / \mathrm{m}^{3}$ for $\mathrm{PM}_{10}$ during 4-6 April, respectively.

\subsection{Meteorological patterns and controlling factors}

Through the analysis of synoptic meteorological charts for this period, it was found that initial weak winds and stable weather patterns prevailed and later followed by transport of Asian dust from Inner Mongolia on 5 April causing the 4-day high of air pollution mixing of anthropogenic pollutants and natural dust particles. Surface synoptic patterns show that from 4-6 April, there is a strong high pressure system located over Yangtze River with the low in Beijing. This typical kind of surface pattern is unfavorable for pollution in Beijing to diffuse and also it is a typical type of weather pattern causing Beijing's serious pollution. Detailed analyzing the synoptic chart during this period, on $500 \mathrm{hPa}$ chart, at $00: 00 \mathrm{Z}$ on 4 April of 2005, Beijing was in strong northwest flow at the back of the East Asia groove. On surface chart, there was a strong high-pressure center located at the southeast of China (Yangtze area), and Beijing lay at the top of the highpressure. From $500 \mathrm{hPa}$ chart at 00:00 Z on 5 April, we could see Beijing was in southwest flow at the front of a groove. Corresponding to $850 \mathrm{hPa}$ and surface of the same time, the high-pressure center still existed, and from surface to high altitude, wind direction of Beijing was southwest. When it came to $06: 00 \mathrm{Z}$, on 5 April, there was a Mongolia cyclone on $500 \mathrm{hPa}$ altitude, and on surface, there were cold front, strong wind and dust storm area in the middle part of Mongolia. And along with the synoptic systems moved to east, later it influenced Beijing area.

By analyzing the variance of average meteorological elements such as pressure and wind speed (Fig. 3) averaged over six observation stations in Beijing from 3-7 April, it was found that the average surface pressure of the six stations was lower than $1010 \mathrm{hPa}$. During the period of 3 April, 16:00 Z to 6 April, 04:00 Z UTC, the average surface wind speed was lower than $2 \mathrm{~m} / \mathrm{s}$, which caused pollutions to accumulate and reached heavy pollution levels with an API more than 350 on 5-6 April. Consequently, the observed $\mathrm{SO}_{2}$ and $\mathrm{PM}_{10}$ concentrations at the IAP site were also very high during this period.

\section{Model description and validation}

The Models-3/CMAQ, which is developed by the U.S. EPA (Byue, et al., 1999), has already been widely used all over the world especially in North America and East Asia. It has successfully applied to investigate the Asian continental outflow of carbon monoxide, ozone, and aerosol sulfate to the western Pacific Ocean by a number of serious researches (Zhang et al., 2002; Uno et al., 2005; Yamaji et al., 2006).

\subsection{Model setup}

In this study, we use the NCAR/Penn State Mesoscale Model (MM5) (Grell et al., 1994), which is based on MRF scheme for the boundary layer process, Grell scheme for convective motion, cloud-cooling scheme for radiation, and some other physical parameterized schemes, to generate the meteorological fields for CMAQ. The outputted meteorological factors are mainly contained of temperature, wind, humidity, pressure, and other parameters requested by CMAQ. The NCAR/NCEP reanalysis data, four times a day with $1^{\circ} \times 1^{\circ}$ resolution, were used for initial and boundary conditions in MM5 model.

Four nested grids at the horizontal resolution of $81 \mathrm{~km}$, $27 \mathrm{~km}, 9 \mathrm{~km}$ and $3 \mathrm{~km}$ with the same center located at $\left(35.0^{\circ} \mathrm{N}, 116.0^{\circ} \mathrm{E}\right)$ were used for MM5 and CMAQ in this 
Table 1. Emissions of major anthropogenic species in this study (Unit: ton/year).

\begin{tabular}{llllllll}
\hline Region & $\mathrm{VOC}$ & $\mathrm{SO}_{2}$ & $\mathrm{NO}_{\mathrm{x}}$ & $\mathrm{CO}$ & $\mathrm{PM}_{10}$ & $\mathrm{PM}_{2.5}$ & $\mathrm{NH}_{3}$ \\
\hline Beijing Municipality & 285551 & 211306 & 227311 & 1021790 & 106890 & 53367 & 69068 \\
Tianjin Municipality & 270000 & 375876 & 178940 & 737041 & 93497 & 37996 & 49981 \\
Hebei Province & 855000 & 1353731 & 686000 & 6806000 & 535055 & 264052 & 846462 \\
Shanxi Province & 401000 & 1467410 & 558000 & 3254000 & 173848 & 66899 & 214950 \\
Shandong Province & 1088000 & 1575245 & 812000 & 7339000 & 684824 & 379516 & 1093000 \\
\hline
\end{tabular}

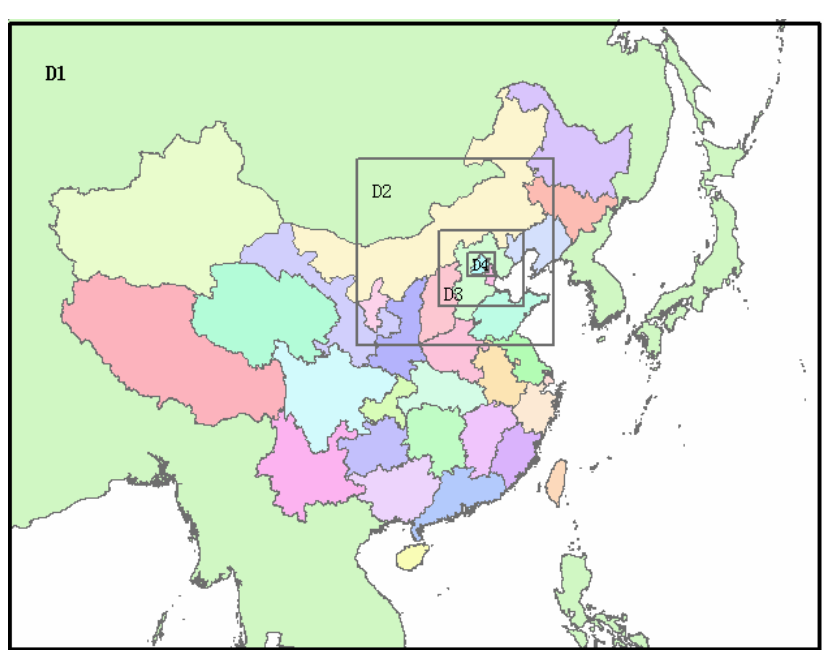

Fig. 4. The four nested domains used for simulation.

study (Fig. 4). The coarse domain covers East Asia with $83 \times 65$ horizontal grids and the second domain with $61 \times 58$ grids includes most provinces of North China. The third domain with $79 \times 70$ grids consists of Beijing and the surrounding cities, and the focus of the fourth domain with $73 \times 64$ grids on urban Beijing. From the first to the fourth domain, the time step is $240 \mathrm{~s}, 80 \mathrm{~s}, 26.67 \mathrm{~s}$ and $8.89 \mathrm{~s}$. Thirty levels were unequally distributed in the vertical from the ground to a level of $100 \mathrm{hPa}$ in MM5. And there are 12 vertical layers extending from the surface to approximately $12 \mathrm{~km}$ in CMAQ, which are reduced from 30 sigma levels of MM5 using the mass-weighted averaging algorithms for reducing the computational costs. Vertical layers of CMAQ are unevenly distributed and surface layer is approximately $35 \mathrm{~m}$. We used the Grell cumulus parameterization, simple ice physics, and the MRF planetary boundary layer in MM5.

The Sparse Matrix Operator Kernel Emissions (SMOKE, 2005) model was applied to prepare the emission inventory and generate gridded emission data for the CMAQ model. There are two emission inventory data are used in this study for SMOKE processing: the regional data from Streets et al. (2003, and personal communications) with $10 \mathrm{~km}$ resolution updated from the TRACE_P emissions inventory, and a detailed local source emissions database of Beijing city with
$1 \mathrm{~km}$ resolution for point, mobile, area, and others sources based on reports of National Projects on Beijing Air Quality Controls. The selected pollutant emissions used in the modeling for Beijing, Tianjin, and the neighboring provinces (Hebei, Shanxi and Shandong) are summarized in Table 1. Figure 5 presents SMOKE output of emission used in the third domain, clearly showing high anthropogenic emissions of $\mathrm{CO}, \mathrm{NO}_{\mathrm{x}}$ and $\mathrm{SO}_{2}$ distributed in urban area of Beijing and Tianjin.

The selected simulation period for analysis is from 2 to 8 April 2005, with 10-day spin-up from 23 March. First three sensitivity runs were conducted to test the uncertainties of NBS emissions impact on Beijing's pollution. In three cases, emissions of local Beijing sources with unchanged, Case 1 with emissions of NBS keeping unchangeable (base run, BR); Case 2 with reduced $50 \%$ emissions of NBS, and Case 3 with added 50\% emissions of NBS. And then a control run (CR) with only NBS was performed and compared with BR to evaluate the impact of NBS on air pollution in Beijing. All of these simulations were conducted with the same meteorological fields produced by MM5.

\subsection{Meteorological comparison of model results with ob- servations}

The rationality of MM5's meteorological simulations of this case are exhibited by several statistical parameters such as MB (the Mean Bias), NMB (the Normalized Mean Bias), NME (the Normalized Mean Error), RMSE (the Root Mean Square Error) and R (the Correlation Coefficient) obtained by traditional statistical methods.

The comparison of meteorological modeling and observation finds out that MM5 simulation is accredited in this study. Six meteorological observation stations which are located in Beijing urban area are used to evaluate model results. They are chosen for their representative and consecutive. The average value of the six sites' observation is compared with the meteorological model output such as temperature (T), relative humidity (RH), wind speed (WS), direction (WD) and pressure $(\mathrm{P})$ in Table 2. The correlation coefficients (R) between the observed T, RH, P, WS and WD, and the simulated ones are high and respectively $0.73,0.71,0.92,0.74$ and 0.50 . So the meteorological MM5 model has the ability to 


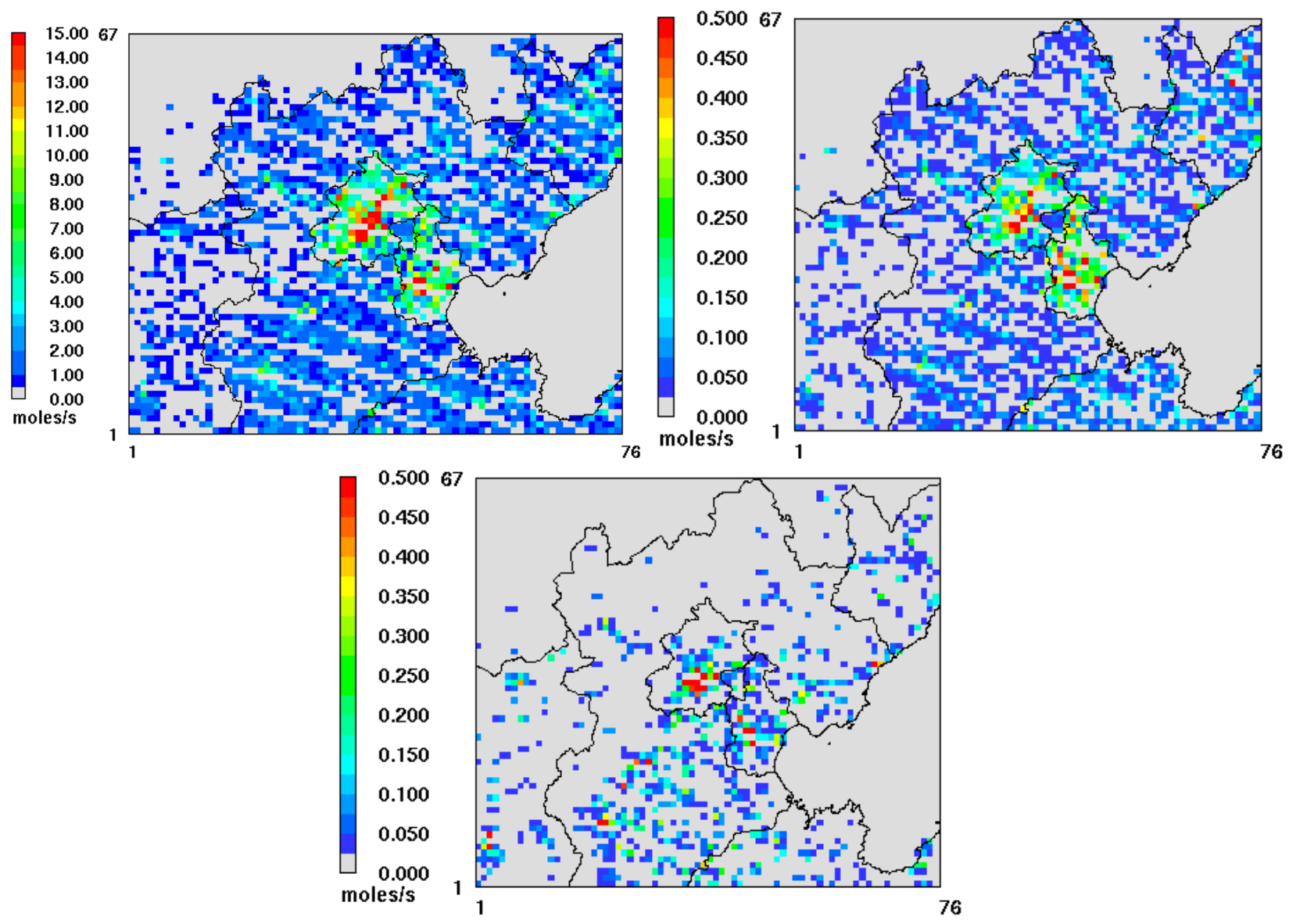

Fig. 5. Spatial distribution of anthropogenic (a) $\mathrm{CO}$, (b) $\mathrm{NO}_{\mathrm{x}}$ and (c) $\mathrm{SO}_{2}$ emission intensity (moles/s) in the third domain with horizontal resolution of $27 \mathrm{~km}$.

Table 2. Statistical summaries of the meteorological comparisons of the model results with observations of average temperature ( $\mathrm{T}$ ), relative humidity (RH), wind speed, direction and pressure, of six observations sites in Beijing.

\begin{tabular}{llllllll}
\hline & Obs. & Sim. & MB & NMB $(\%)$ & NME $(\%)$ & RMSE & R \\
\hline $\mathrm{T}\left(^{\circ}\right)$ & 15.6 & 15.5 & -0.1 & -0.8 & 21.4 & 3.8 & 0.73 \\
RH $(\%)$ & 46 & 49 & 2.2 & 4.9 & 26.2 & 15.4 & 0.71 \\
Pressure $(\mathrm{hPa})$ & 1005 & 1006 & 0.4 & 0.1 & 0.3 & 3.7 & 0.92 \\
Wind speed $(\mathrm{m} / \mathrm{s})$ & 8.9 & 13.6 & 1.4 & 56.4 & 58.2 & 1.8 & 0.74 \\
Wind direction $\left(^{\circ}\right)$ & 170 & 159 & -10.8 & -6.4 & 34.0 & 73.5 & 0.50 \\
\hline
\end{tabular}

simulate the different meteorological variables. From other statistical parameters data, such as MB, NMB, NME and RMSE, we can see that the model can better simulate the characteristics of T, RH and P factors. The NMB and NME values for WS are higher than 50\%; this indicates that the model slightly overestimates the wind speed. The MB and RMSE are low and the R value is higher for WS, so the model results of WS are reliable.
3.3 Comparison of model results with observation and MODIS AOD

Figure 6 shows the comparison of simulated $\mathrm{SO}_{2}$ and $\mathrm{PM}_{10}$ concentrations with observed data at $47 \mathrm{~m}\left(\mathrm{SO}_{2}\right)$ and $8 \mathrm{~m}$ $\left(\mathrm{PM}_{10}\right)$ height of IAP tower. The model simulated the magnitude and the diurnal patterns of $\mathrm{SO}_{2}$ and $\mathrm{PM}_{10}$ well. The correlation coefficient of $\mathrm{SO}_{2}$ and $\mathrm{PM}_{10}$ between the model and observation is higher than 0.70 and 0.60 , respectively. The 


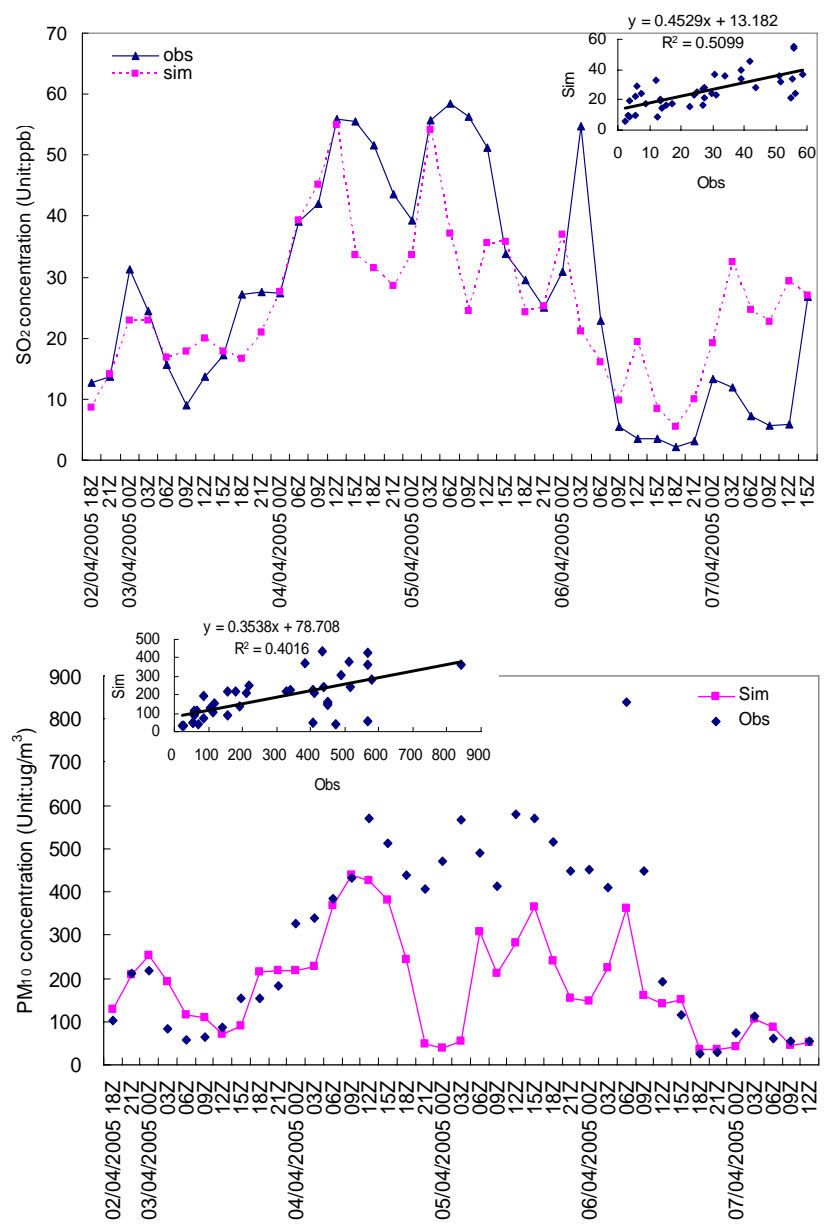

Fig. 6. Comparison of observed and simulated $\mathrm{SO}_{2}$ (a) and $\mathrm{PM}_{10}$ (b) concentration of three hour average at IAP site from 2 April to 7 April 2005 (UTC).

model can also simulate the variations of the particles during this episode, but the simulation generally under predicted particle concentrations due to uncertainties in emissions and a lack of dust emission module in the current CMAQ system.

The model results are also compared with MODIS optical depth data. Satellite remote sensing provides a means to derive aerosol distribution at global and regional scales. The Moderate Resolution Imaging Spectroradiometer (MODIS) aboard two of NASA's Earth Observing System (EOS) satellites (Terra and Aqua) began a new era of aerosol remote sensing over land (Chu et al., 2003). Aerosol optical depth (AOD) products from MODIS have been verified by the sunphotometer observations in some regions of China ( $\mathrm{Li}$ et al., 2003) and used to research air pollution in and around Beijing areas (Li et al., 2005). The researched results show that the MODIS AOD data have high accuracy and can better describe the regional and urban pollution distribution. Figure 7a shows the spatial distribution of MODIS Level 2 prod-
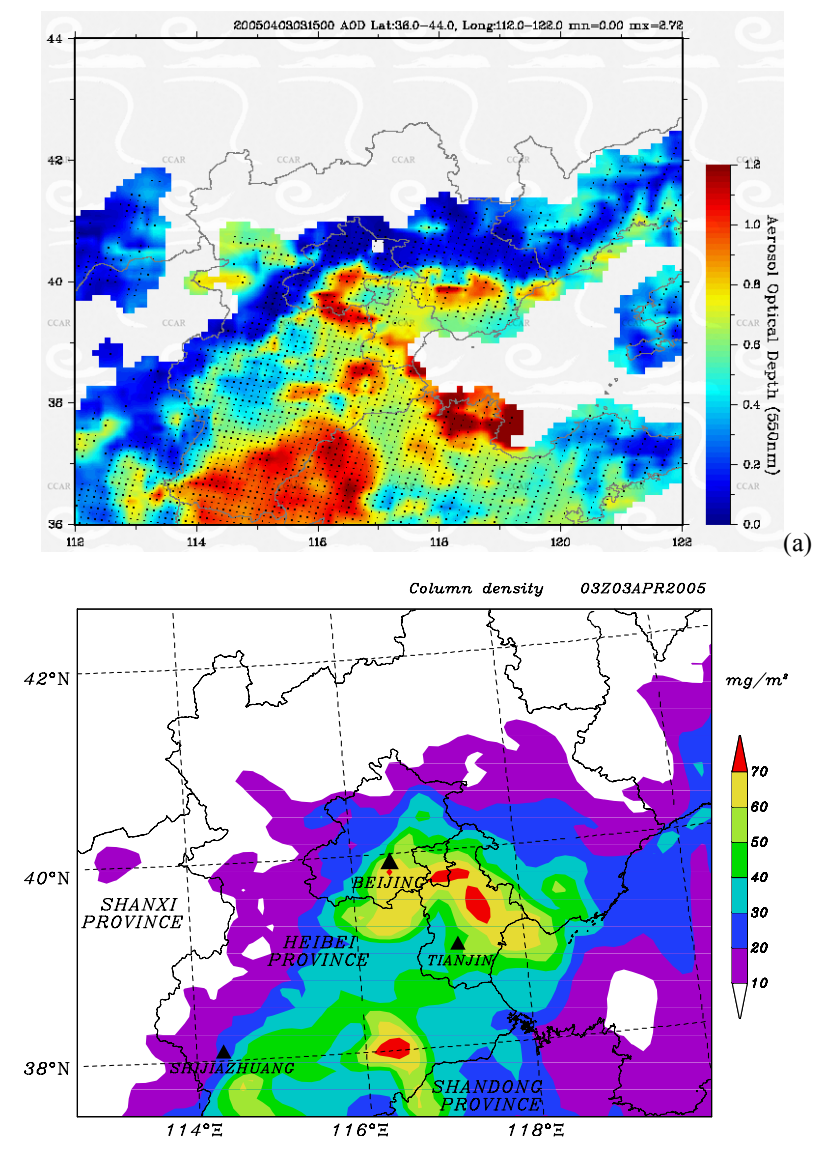

(b)

Fig. 7. (a) Aerosol Optical Depth spatial distributions by MODIS at 03:15 Z on 3 April 2005 (b) Model simulated PM $_{10}$ column density of Beijing and surrounding areas at 03:00 (UTC) on 3 April 2005.

ucts of AOD (Version 4) with $10 \mathrm{~km}$ nadir spatial resolution in and around Beijing areas on 3 April 2005, 03:15 Z. Data over ocean parts are not used for larger uncertainty is usually caused by high concentration of sediment. Regions in the north part of the figure are also blank for the surface is too bright (not covered with dense vegetation) to get precise aerosol retrieval. Figure $7 \mathrm{~b}$ is the model simulated $\mathrm{PM}_{10}$ column density of Beijing and surrounding areas on 3 April 2005, 03:00 Z. Compared Fig. 7a with Fig. 7b, it can be seen that at in most areas the distributions patterns of simulated column density are consistent with MODIS AOD. In the coastal areas of Bo Hai Bay, about $200 \mathrm{~km}$ away from Beijing, MODIS observed larger AOD values than our model. The difference between the two sources is mainly due to MODIS AOD retrieval errors near estuary and coastal areas with high sediment concentration in the water ( $\mathrm{Li}$ et al., 2003). AOD values in the Beijing area corresponding to our model grids are derived from MODIS level 2 products according to the nearest valid data within the scope from $39^{\circ} \mathrm{N}$ to $40.5^{\circ} \mathrm{N}$, and from $115.5^{\circ} \mathrm{E}$ to $117^{\circ} \mathrm{E}$. The 

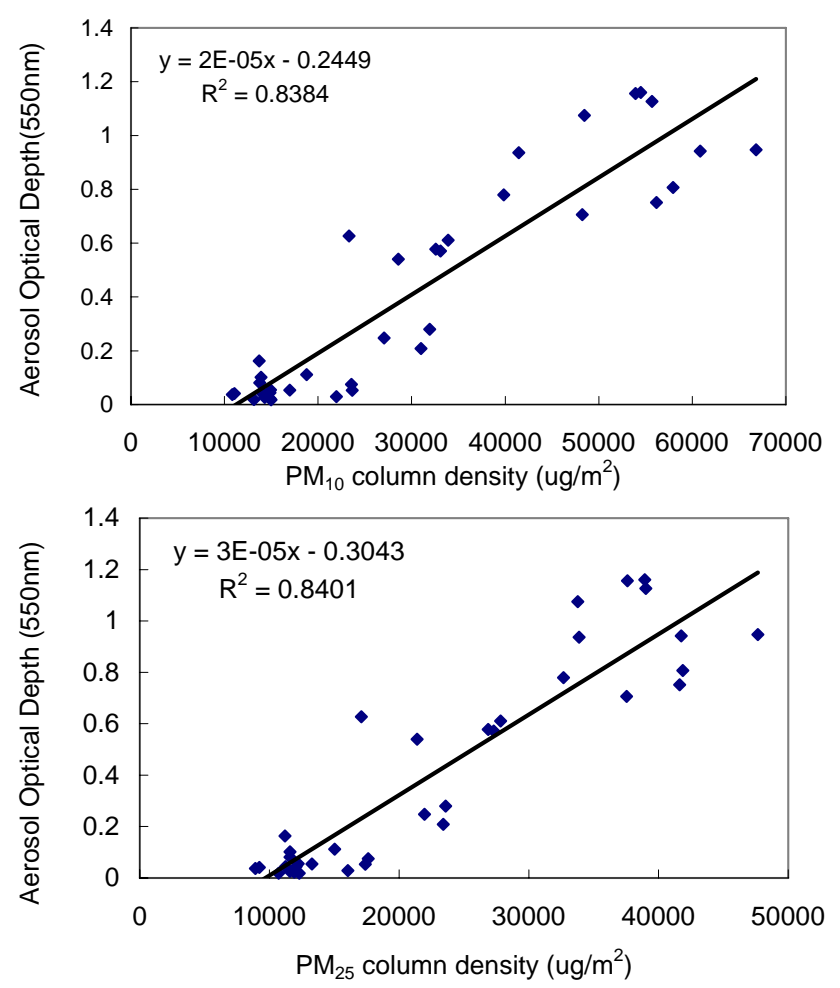

Fig. 8. Correlation coefficient of simulated $\mathrm{PM}_{10}$ (a) and $\mathrm{PM}_{2.5}$ (b) column density with Aerosol Optical Depth.

correlation coefficient between MODIS AOD and model results are higher than 0.90 (R-squred 0.84) (Fig. 8).

\section{Results and discussions}

4.1 Temporal and spatial distribution of simulated $\mathrm{PM}_{10}$ concentration

Figure 9a shows the simulated altitude-time cross sections of $\mathrm{PM}_{10}$ concentrations at the IAP site. From 4-6 April of $2005, \mathrm{PM}_{10}$ concentrations below $200 \mathrm{~m}$ were very high, especially at night, which corresponded to the lower atmospheric boundary layer (ABL) height (Fig. 9b) from 12:00 Z to $00: 00 \mathrm{Z}$ (UTC), preventing atmospheric pollutants from dispersing away. Also during this period the surface wind speed was very weak especially from 4 April, 9:00Z to 5 April, 00:00 Z and from 5 April, 12:00 Z to 6 April, 00:00 Z (UTC) with a wind speed of less than $1.0 \mathrm{~m} / \mathrm{s}$ (Fig. 3).

\subsection{Sensitive models results of NBS emissions}

Two sensitivity runs are conducted and compared with the base run to show the correlation of NBS emissions with air pollution in Beijing. Timely variance of $\mathrm{PM}_{10}$ and $\mathrm{PM}_{25}$ concentration along Beijing under case 1 (base case), case 2,
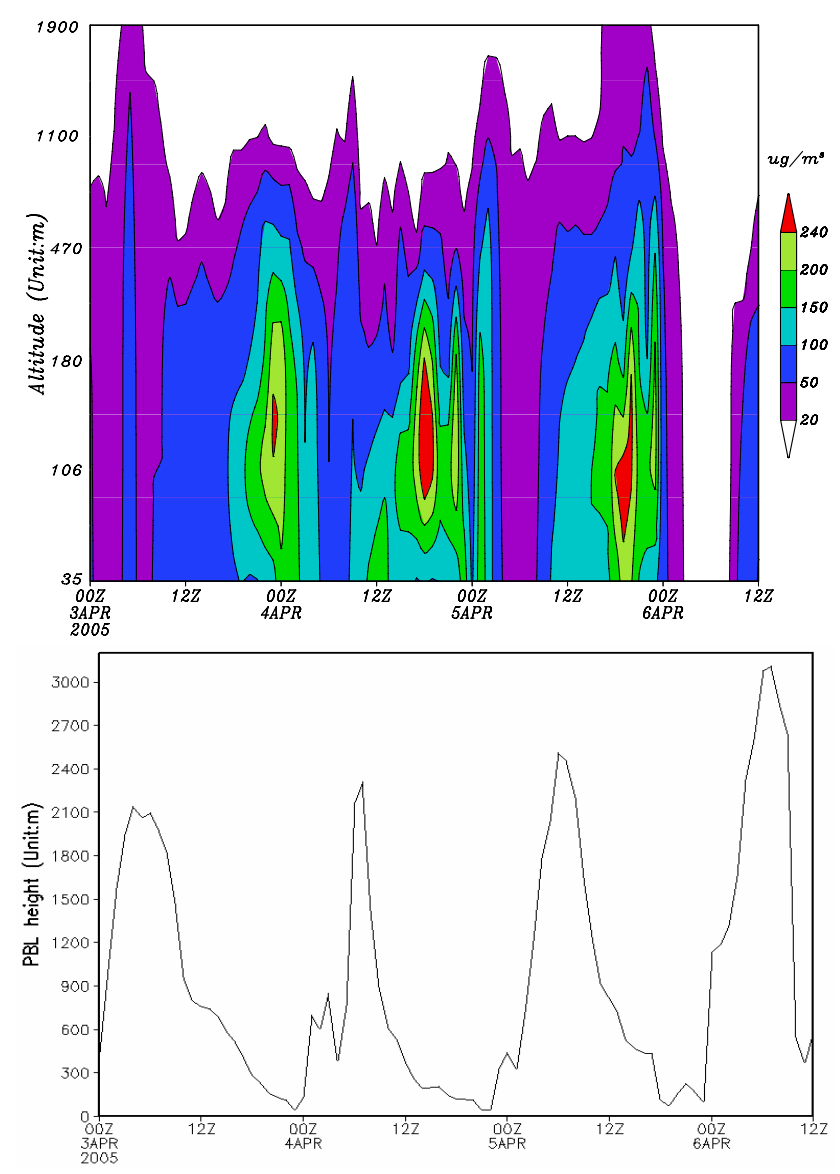

Fig. 9. Vertical distributions of simulated $\mathrm{PM}_{10}$ concentration and calculated atmospheric boundary layer (ABL) height by MM5 along IAP site (a) Altitude-time cross sections of $\mathrm{PM}_{10}$ concentrations (b) ABL height (m).

case 3, and the difference between the cases for $\mathrm{PM}_{10}$ and $\mathrm{PM}_{25}$ are shown in Fig. 10. Figure 10 shows that the particle concentration variance patterns are similar under the reduced $50 \%$ emissions of NBS, added $50 \%$ emissions of NBS and base conditions during the episode. The differences between case 1 and case 2, and case 3 and case 1 are nearly the same. It shows that the impact of NBS emissions on air pollution in Beijing is almost linear.

4.3 NBS contributions to $\mathrm{SO}_{2}$ and particle in Beijing during the episode

Figure 11 represents the simulated $\mathrm{SO}_{2}$ and $\mathrm{PM}_{10}$ concentrations in the fourth nested domain $(3 \mathrm{~km})$ at $02: 00 \mathrm{Z}$, on 5 April. The horizontal distributions of $\mathrm{SO}_{2}$ and $\mathrm{PM}_{10}$ are shown in Figs. 11a and $\mathrm{c}$ with all sources and in Figs. 11b and $\mathrm{d}$ for only NBS, respectively. Figure 11a shows that $\mathrm{SO}_{2}$ concentrations at most urban Beijing are higher than $30 \mathrm{ppb}$, peaking around at $110 \mathrm{ppb}$ in the west of urban Beijing. Compared with Fig. 11b, the contribution of NBS to 

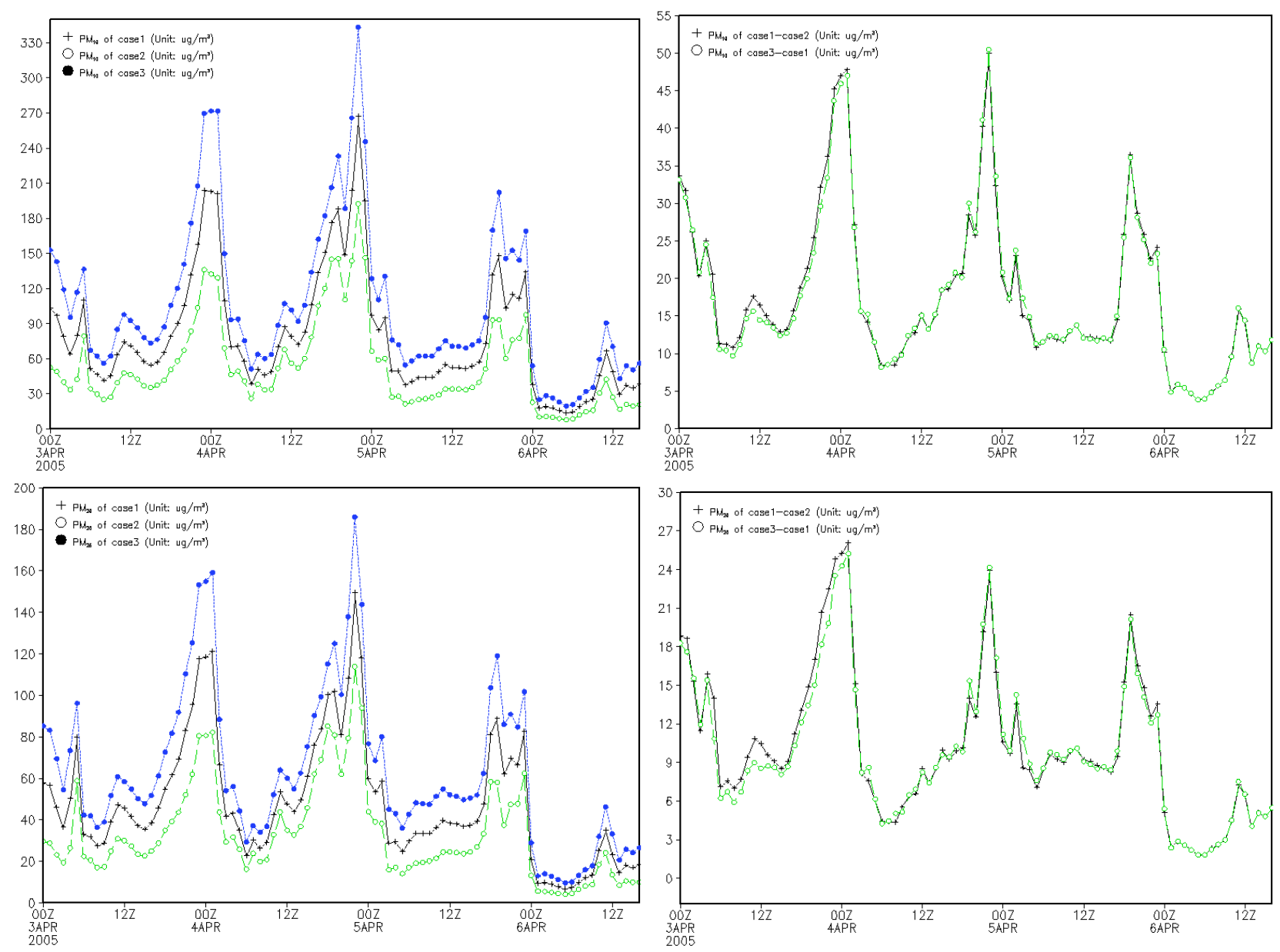

Fig. 10. Comparison of simulated temporal variance of $\mathrm{PM}_{10}$ (a) and $\mathrm{PM}_{25}$ (c) concentration along Beijing under Case 1 (base case), Case 2 , Case 3, and the difference between the cases for $\mathrm{PM}_{10}$ (b) and $\mathrm{PM}_{25}$ (d) from 3 April 00Z to 6 April 2005 12Z (UTC). Case 1 with emissions of NBS keeping unchangeable (base run, BR); Case 2 with reduced 50\% emissions of NBS, and Case 3 with added 50\% emissions of NBS.

$\mathrm{SO}_{2}$ in most areas of urban Beijing is about $6 \mathrm{ppb}$, with higher contributions in southeast area. The patterns of $\mathrm{PM}_{10}$ concentrations are similar to those of $\mathrm{SO}_{2}$, with a maximum of more than $210 \mu \mathrm{g} / \mathrm{m}^{3}$ at west of urban Beijing (Fig. 11c). The contribution of NBS for $\mathrm{PM}_{10}$ concentration in Beijing is about $10-15 \mu \mathrm{g} / \mathrm{m}^{3}$ (Fig. 11d).

The following formula was used to calculate the percentage contributions (PC) from NBS to $\mathrm{PM}_{10}, \mathrm{PM}_{2.5}, \mathrm{SO}_{2}$ and soil (soil particle with diameter between $2.5 \mu \mathrm{m}$ and $10 \mu \mathrm{m}$ ):

$\mathrm{PC}=C(C R) \times 100 / C(B R)$

where $C(C R)$ and $C(B R)$ are the simulated concentrations of $\mathrm{PM}_{10}, \mathrm{PM}_{2.5}, \mathrm{SO}_{2}$ or Soil, with BR run (all sources) and CR run (only NBS), respectively.

Using the results from the two runs, the distribution patterns of $\mathrm{PC}$ for $\mathrm{PM}_{10}$ and $\mathrm{PM}_{2.5}$ were obtained. $\mathrm{PM}_{10}$ and $\mathrm{PM}_{2.5}$ generally show similar patterns, indicating the same source regions for both of them. The contributions of NBS are variously spatially distributed over urban Beijing. In order to evaluate the effect of NBS on air pollution in different area of Beijing during this episode, the urban area is divided into five regions such as northwest (NW), southwest (SW), center, northeast (NE), southeast (SE). The percentage contribution of NBS to each region is calculated by using weighted mean method and summed up in Table 3. The average percentage (AVE) for all urban area is the average of these five parts. From the table, we can see that the average contribution of NBS to $\mathrm{PM}_{2.5}$ is $39 \%$, with maximum up to $53 \%$ at the northwest of urban area and only $15 \%$ at southwest. The spatial distribution pattern of contribution ratio for $\mathrm{PM}_{10}$ is very close to $\mathrm{PM}_{2.5}$, but with slightly less than $\mathrm{PM}_{2.5}$. The maximum weighted average contribution to $\mathrm{PM}_{10}$ is $43 \%$ at the northwest of Beijing urban area and the minimum is $10 \%$ at the southwest. And the average contribution for $\mathrm{PM}_{10}$ is $30 \%$. The average contribution of NBS for $\mathrm{SO}_{2}$ is $18 \%$ with the maximum up to $26 \%$ at the southeast of 

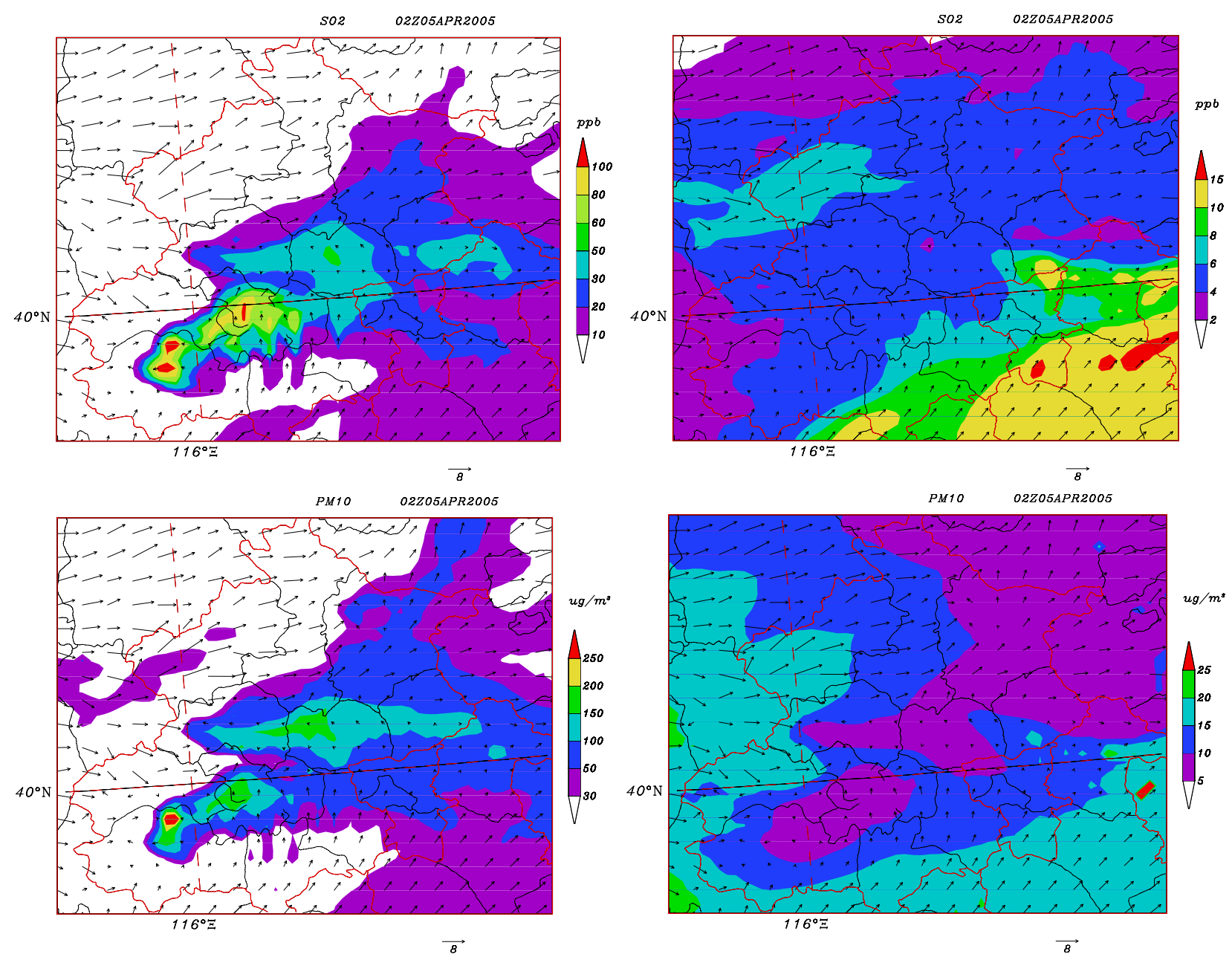

Fig. 11. Horizontal distributions of simulated $\mathrm{SO}_{2}$ and $\mathrm{PM}_{10}$ concentrations over Beijing area at 02:00 (UTC) on 5 April 2005. (a) For $\mathrm{SO}_{2}$ of all sources; (b) for $\mathrm{SO}_{2}$ of sources outside Beijing; (c) same as (a), but for $\mathrm{PM}_{10}$; (d) same as (b), but for $\mathrm{PM}_{10}$.

urban area and the minimum $13 \%$ at the northwest. For soil, the spatial distribution pattern of contribution is very like that of $\mathrm{SO}_{2}$, and the average contribution of NBS to soil is $10 \%$ with the maximum at the southeast and the minimum at the northwest.

Therefore, for $\mathrm{PM}_{2.5}$ and $\mathrm{PM}_{10}$, the order of contribution of NBS from big to small is NW, SE, NE and SW. But for $\mathrm{SO}_{2}$ and soil, it is different from that of $\mathrm{PM}_{10}$, the order from big to small is SE, SW, NE and NW. Table 3 also indicates that the average contributions of NBS are different for each pollutant, with the order of $\mathrm{PM}_{25}>\mathrm{PM}_{10}>\mathrm{SO}_{2}>$ soil during this episode.

It can also be elucidated from the table that the NBS contribution of fine particles is larger than that of coarse particles to Beijing background PM levels as the fine particles are much easier to be long-range transported.

\subsection{Pathways of NBS transporting to Beijing}

The vertical altitude-time cross section and the west-east cross section of $\mathrm{PM}_{10}$ flux along Beijing are shown in Figs. 12 and 13 , respectively. $\mathrm{PM}_{10}$ flux is calculated by the following formula:

flux $=C \times V$

Where $C$ is the simulated concentration of $\mathrm{PM}_{10}$ and $V$ is the wind velocity.

From 3 to 6 April, strong $\mathrm{PM}_{10}$ fluxes were calculated coming from the southwest to the northeast of Beijing, especially during nighttime. In order to clearly reveal the correlation between the NBS contribution to $\mathrm{PM}_{10}$ in Beijing, the temporal variance of $\mathrm{PM}_{10}$ concentration, $\mathrm{PM}_{10}$ flux and the contribution of NBS along Beijing are shown in Fig. 14. From Fig. 14, we can see that the peak $\mathrm{PM}_{10}$ flux was seen at about 14:00 Z on 5 April 2005, which corresponded to the 


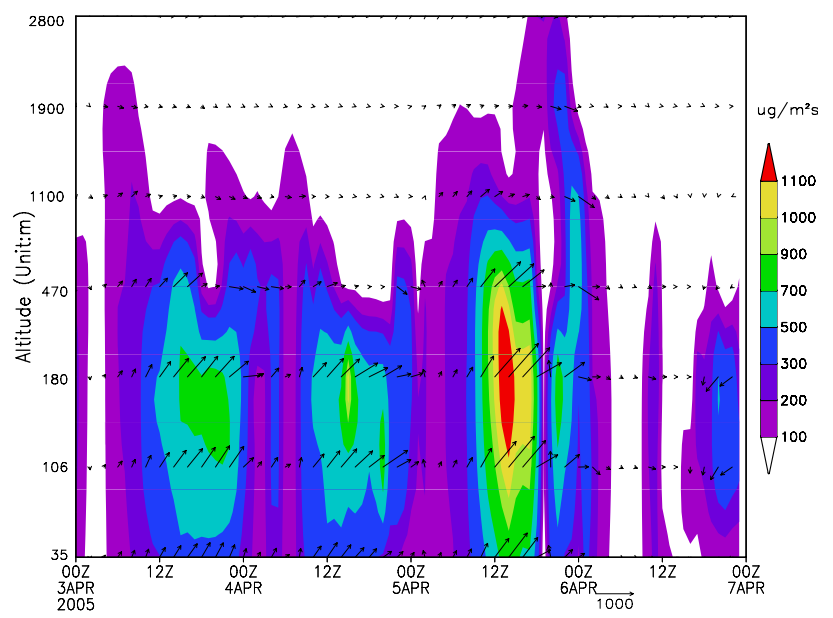

Fig. 12. Altitude-time cross sections of $\mathrm{PM}_{10}$ flux (Unit: $\mu \mathrm{g} \mathrm{m}^{-2} \mathrm{~s}^{-1}$ ) along Beijing from 3 April to 7 April 2006.

Table 3. The weighted average percentage contributions of NBS to $\mathrm{SO}_{2}$ and particle in urban Beijing.

\begin{tabular}{lllllll}
\hline Area & NW & SW & Center & NE & SE & AVE \\
\hline $\mathrm{PM}_{2.5}$ & $53 \%$ & $15 \%$ & $35 \%$ & $44 \%$ & $50 \%$ & $39 \%$ \\
$\mathrm{PM}_{10}$ & $43 \%$ & $10 \%$ & $25 \%$ & $34 \%$ & $37 \%$ & $30 \%$ \\
$\mathrm{SO}_{2}$ & $13 \%$ & $18 \%$ & $15 \%$ & $17 \%$ & $26 \%$ & $18 \%$ \\
soil & $5 \%$ & $10 \%$ & $10 \%$ & $10 \%$ & $15 \%$ & $10 \%$ \\
\hline
\end{tabular}

peak value of contribution percentage to $\mathrm{PM}_{10}$ at this time. The peak $\mathrm{PM}_{10}$ flux was up to $1100 \mu \mathrm{g} \mathrm{m}^{-2} \mathrm{~s}^{-1}$ at an altitude of about $200 \mathrm{~m}$ and correspondingly the peak contribution ratio of NBS to $\mathrm{PM}_{10}$ was up to $60 \%$.

Figure 14 shows that the $\mathrm{PM}_{10}$ flux peaks at the same time as the maximum of the contribution to $\mathrm{PM}_{10}$ occurring, with a delayed $\mathrm{PM}_{10}$ concentration peak. At 18:00 Z on 3 April, 15:00 Z on 4 April and at 14:00 Z on 5 April, the contribution percentage of NBS was very large with a strong $\mathrm{PM}_{10}$ flux imported from surrounding areas into Beijing, which induced the high $\mathrm{PM}_{10}$ concentration at later time (at 23:00 Z on 3 April, 20:00 Z on 4 April and at 20:00 Z on 5 April). It indicates that the contribution of surrounding sources plays a very important role in forming high pollution concentration in Beijing during this episode.

From the horizontal distribution chart of $\mathrm{PM}_{10}$ fluxes (Fig. 15), it can be seen that strong particle fluxes were transported from the southwest area of Beijing by southwest wind. At $06: 00 \mathrm{Z}$ on 5 April, the flux center located at the boundary of Hebei province from Shanxi province. At 10:00 Z on 5 April, the high flux center moved to the northeast of Shijiazhuang. Later, the flux peak reached Beijing at about 14:00 Z. Therefore, the dominant transport pathway for NBS effecting Beijing was by the west and southwest flow dur-
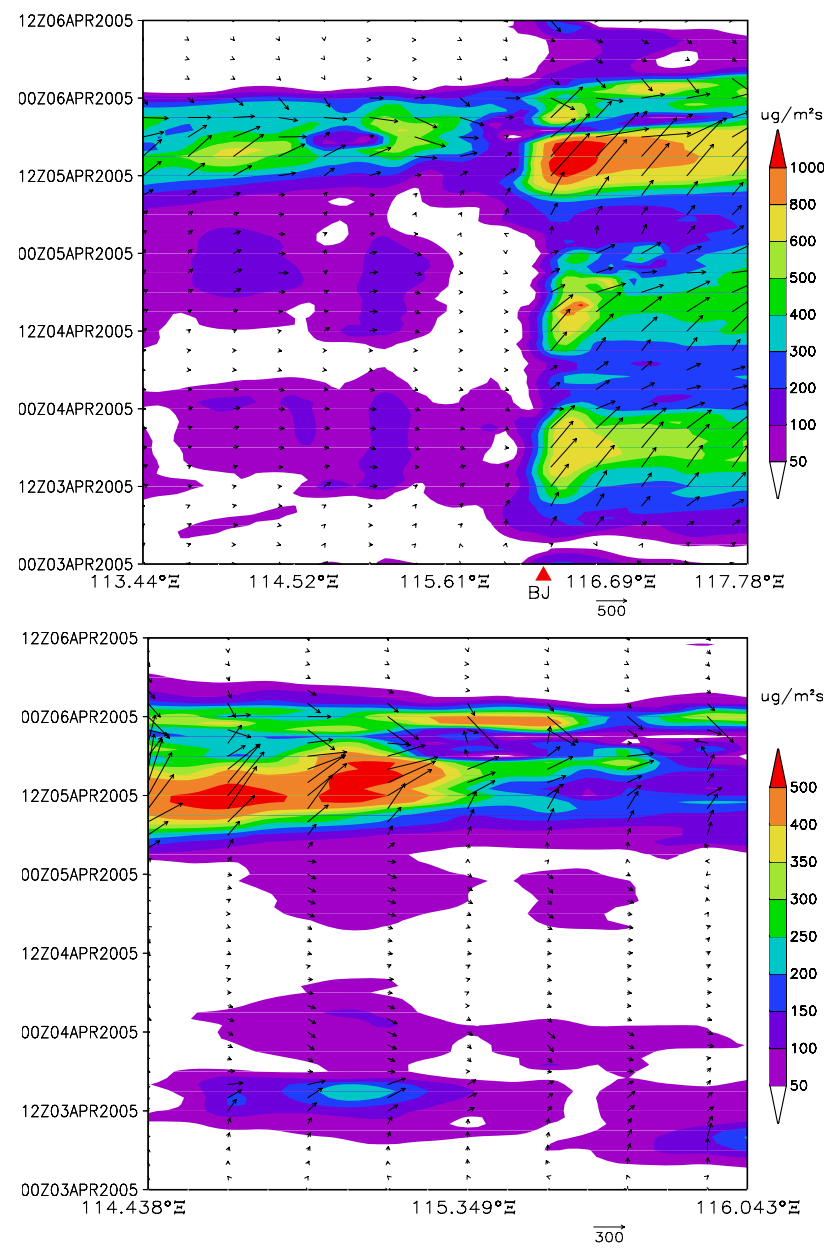

Fig. 13. (a) West-east cross section of $\mathrm{PM}_{10}$ flux (Unit: $\mu \mathrm{g} \mathrm{m}^{-2} \mathrm{~s}^{-1}$ ) along Beijing from 3 April 00:00 to 6 April 12:00 (UTC), (b) Cross-section of $\mathrm{PM}_{10}$ flux (Unit: $\mu \mathrm{g} \mathrm{m}^{-2} \mathrm{~s}^{-1}$ ) along SW-NE pathway from 3 April 00:00 to 6 April 12:00 (UTC).

ing this episode. Meteorological analysis (Sect. 2.3) shows that during this period, Beijing was controlled by southwest wind on $850 \mathrm{hPa}$ and surface, and located at low pressure on groove. This type of meteorological pattern offers a convenient condition for sources located at southwest region to be transported into Beijing. And also after 5 April, the floating dust storms brought by a strong Mongolia cyclone across north China strengthened this process.

\section{Summary}

The Models-3/CMAQ coupled with MM5 and SMOKE module was applied to evaluate the contributions of NBS to high $\mathrm{SO}_{2}$ and particles pollutants in Beijing during 3-7 April 2005. Comparisons of model results with observed data at the IAP tower and MODIS AOD showed that the model captured the main observed features of this serious pollution 


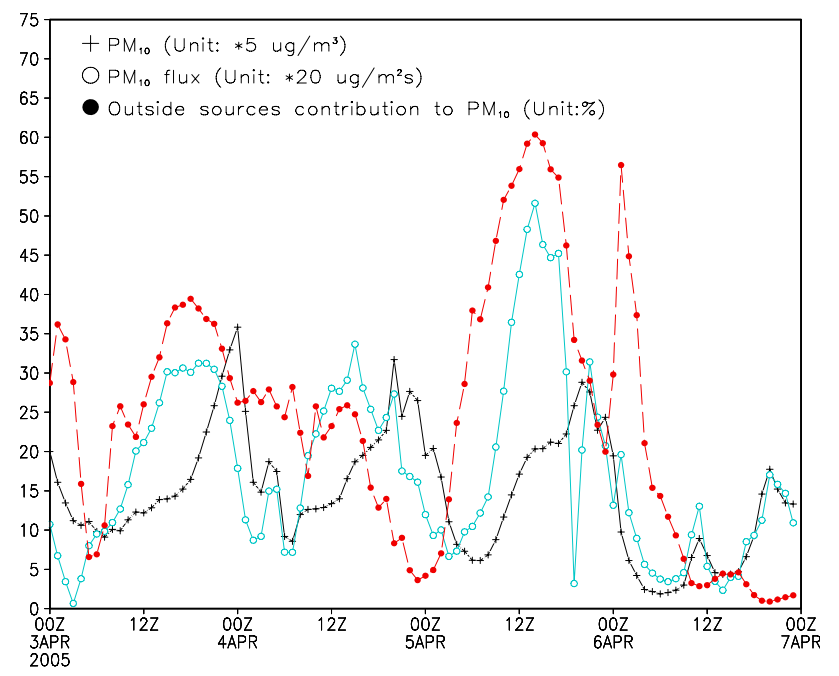

Fig. 14. Temporal variance of $\mathrm{PM}_{10}$ concentration, $\mathrm{PM}_{10}$ flux and contribution of sources outside Beijing to $\mathrm{PM}_{10}$ along Beijing (UTC).

episode. The correlation coefficient for $\mathrm{SO}_{2}$ between the model and observed data was averaged around 0.70 while the correlation coefficient for the modeled column loading of particles and MODIS AOD reached 0.90. The spatial distributions of $\mathrm{SO}_{2}$ and $\mathrm{PM}_{10}$ simulated by the model showed that high concentrations were transported from southwest area of Beijing to the northeast by west and southwest winds. This was also confirmed with synoptic chart analysis and transport flux analysis during this period. The sensitivity studies indicated that NBS contributions varied temporally and spatially for certain pollution species. For $\mathrm{PM}_{2.5}$, the maximum weighted average contribution was up to $53 \%$ at the northwest of urban area, the least was about $15 \%$ at southwest. For $\mathrm{PM}_{10}$, spatial distribution and temporal variance of contributions were close to those of $\mathrm{PM}_{2.5}$, but slightly less. Model results also revealed that NBS contributes more to fine particle than coarse particles. The average contributions of $\mathrm{SO}_{2}$ and soil were $18 \%$ and $10 \%$. The calculated transport flux results show that the $\mathrm{PM}_{10}$ flux peak and percentage contribution peak of NBS to $\mathrm{PM}_{10}$ happened almost simultaneously with a delay the $\mathrm{PM}_{10}$ concentrations.

This study presents a well behaved modeling system for investigating the Beijing urban pollutions and source contributions. For a comprehensive analysis of Beijing air pollutions, more observational data are needed for model validations and longer simulations are required to obtain the seasonal variations of NBS contributions. It is noticed that although this method emission switch on/off method is widely used to estimate the contribution of target emissions by most of modellers (Streets et al., 2006), it may cause significant bias/errors to estimate the non-linear source-reception relations. In a nonlinear system with many factors involved, the total impacts of all factors are not linearly additive of the
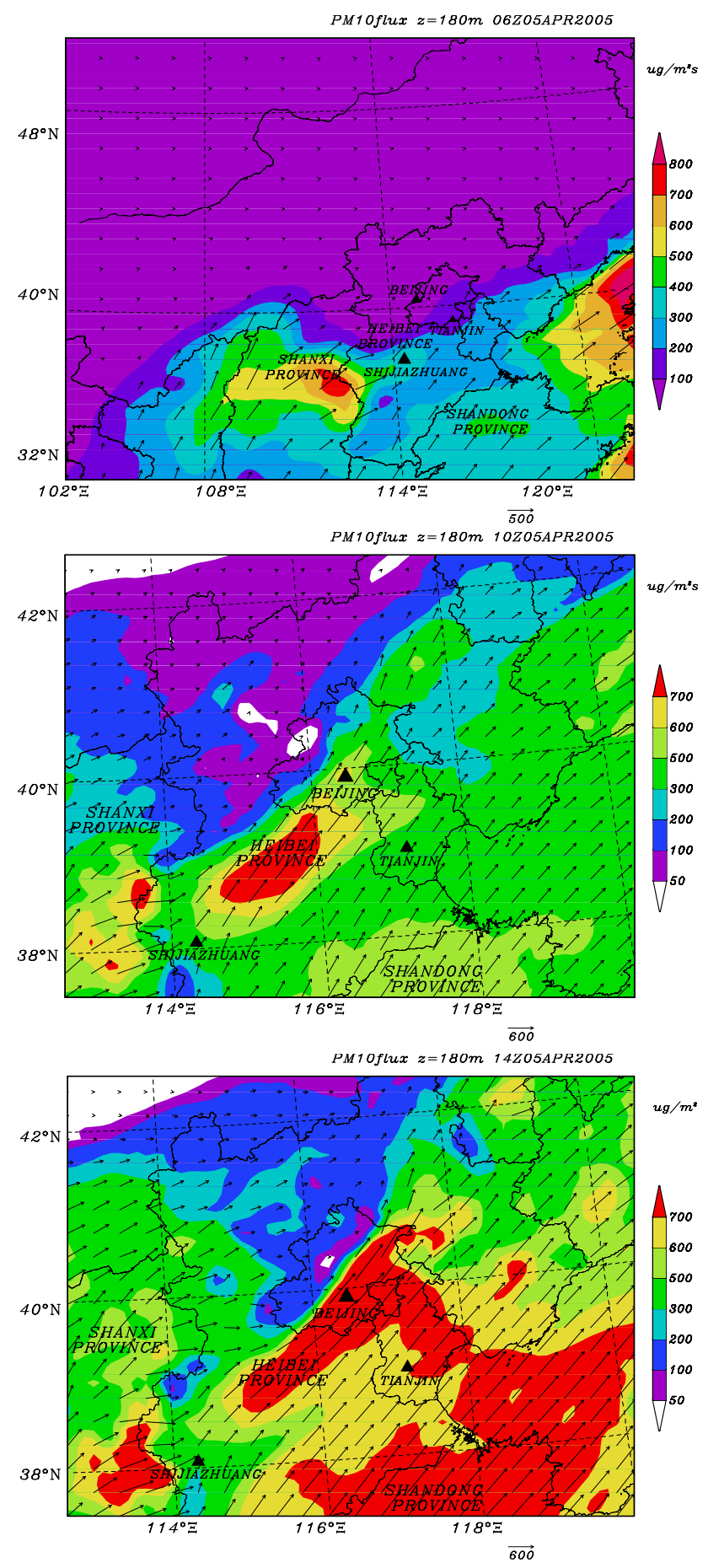

Fig. 15. Horizontal distributions of $\mathrm{PM}_{10}$ fluxes at altitude about $180 \mathrm{~m}$ at (a) 06:00 Z, (b) 10:00 Z, and (c) 14:00 Z on 5 April (Unit: $\left.\mu \mathrm{g} \mathrm{m}^{-2} \mathrm{~s}^{-1}\right)$.

contribution from each factor. The contribution of one factor in presence of other factors can be determined by taking the difference between a model run including all factors 
and another model run with the factor of interest excluded. For $\mathrm{SO}_{2}$, it is probably fine, but for $\mathrm{PM}$, there are too many species with complex non-linear reaction and evolution to make uncertainty quite large. The application of the current modeling results for control should be careful but it is an important first step to address the concerns on the regional air quality control needs for Beijing Olympic 2008.

Acknowledgements. This study was supported by Key Project of Chinese Academy of Sciences (KZCX3-SW-341), Natural Science Foundation of China (40490265) and Chinese Ministry of Science and Technology (2002CB410802 and 2005CB422205). The authors gratefully acknowledge D. Street for offering emission inventory of East Asia, three anonymous referees and P. Castellanos at University of Maryland to revise the manuscript.

Edited by: R. Volkamer

\section{References}

Chu, D. A., Kaufman, Y. J., Zibordi, G., Chern, J. D., Mao, J. T., Li, C. C., and Holben, B. N.: Global monitoring of air pollution over land from the Earth Observing System-Terra Moderate Resolution Imaging Spectroradiometer (MODIS), J. Geophys. Res. Atmos., 108D(21), 4661, doi:10.1029/2002JD003179, 2003.

Draxler, R. R. and Rolph, G. D.: HYSPLIT (HYbrid Single-Particle Lagrangian Integrated Trajectory) Model access via NOAA ARL READY Website (http://www.arl.noaa.gov/ready/hysplit4.html), NOAA Air Resources Laboratory, Silver Spring, MD, 2003.

Grell, G. A., Dudhia, J., and Stauffer, D. R. A.: A description of the Fifth Generation Penn 15 State/NCAR Mesoscale Model (MM5), NCAR Technical Note, 1994, NCAR/TU-398+STR, $138,1994$.

Li, C. C., Mao, J. T., Lau, K. H. A., Chen, J. C., Yuan, Z. B., Liu, X. Y., Zhu, A. H., and Liu, G. Q.: Characteristics of distribution and seasonal variation of aerosol optical depth in eastern China with MODIS products, Chinese Sci. Bull., 48(22), 2488-2495, 2003.

Li, C. C., Mao, J. T., Lau, K. H. A., Yuan, Z. B., Wang, M. H., and Liu, X. Y.: Application of MODIS satellite products on the air pollution research in Beijing, Science in China Series D, 35, 209-219, 2005.

SMOKE, MCNC: http://cf.unc.edu/cep/empd/products/smoke, 2005.

Ren, Z. H., Wan, B. T., Yu, T., et al.: Influence of Weather System of Different Scale s on Pollution Boundary Layer and the Transport in Horizontal Current Field, Res. Environ. Sci., 17(1), 7-13, 2004.
Rolph, G. D.: Real-time Environmental Applications and Display System (READY) Website (http://www.arl.noaa.gov/ready/ hysplit4.html), NOAA Air Resources Laboratory, Silver Spring, MD, 2003.

Streets, D. G., Bond, T. C., Carmichael, G. R., et al.: An inventory of gaseous and primary aerosol emissions in Asia in the year 2000, J. Geophys. Res., 108(D21), 8809, doi:10.1029/2002JD003093, 2003.

Streets, D. G., Fu, J. S., Jang, C. J., Hao, J., He, K., Tang, X., Zhang, Y., Wang, Z., Li, Z., Zhang, Q., et al.: Air quality during the 2008 Beijing Olympic Games, Atmos. Environ., 41(3), 480492, 2007.

Su, F. Q., Gao, Q. X., Zhang, Z. G., et al.: Transport Pathways of Pollutants from Outside in Atmosphere Boundary Layer, Res. Environ. Sci., 17(1), 26-29, 2004.

Sun, Y. L., Zhuang, G. S., Wang, Y., Han, L. H., et al.: The airborne particulate pollution in Beijing - Concentration, composition, distribution and sources, Atmos. Environ., 38, 5991-6004, 2004.

Uno, I., Ohara, T., Sugata, S., et al.: Development of RAMS/CMAQ Asian Scale Chemical Transport Modeling System, J. Jpn. Soc. Atmos. Environ., 40(4), 148-164, 2005.

U.S. EPA: Science Algorithms of the EPA Models-3 Community Multiscale Air Quality Model (CMAQ) Modeling System, U.S. EPA Report EPA/600/R-99/030, Research Triangle Park, NC, 1999.

Xu, X. D., Zhou, L., Zhou, X. J., et al.: Urban Environment Region Influenced by Surrounding Sources During Serious Atmospheric Pollution Process, SCIENCE IN CHINA Ser. D Earth Sciences (in Chinese), 34(10), 958-966, 2004.

Yamaji, K., Ohara, T., Uno, I., et al.: Analysis of seasonal variation of ozone in the boundary layer in East Asia using the Community Multi-scale Air Quality model: What controls surface ozone level over Japan?, Atmos. Environ., 40(10), 1856-1868, 2006.

Yan, P. and Huang, J.: Long Term Simulation of $\mathrm{SO}_{2}$ in Beijing and Calculation and Evaluation of Effects of Different Type Sources on SO2, Science in China, 35D, 167-176, 2005.

Zhang, M. G., Uno, I., Sugata, S., et al.: Numerical study of boundary layer ozone transport and photochemical production in East Asia in the wintertime. Geophys. Res. Lett., 29(11), 1545, doi:10.1029/2001GL014368, 2002.

Zhang, M. G., Uno, I., Akimoto, H., et al.: Large-scale structure of trace gas and aerosol distributions over the western Pacific Ocean during the Transport and Chemical Evolution Over the Pacific (TRACE-P) experiment, J. Geophys. Res., 108(D21), 8820, doi:1011029P2002JD002946, 2003.

Zhang, Z. G. , Gao, Q. X., Han, X. Q., et al.: The study of pollutant transport between the cities in North China, Res. Environ. Sci. (in Chinese), 17(1), 14-20, 2004. 